\title{
EVOLUTION AND VIABILITY OF STECKEL MILLS*
}

Karl Berger ${ }^{1}$ John Frenn ${ }^{2}$

\begin{abstract}
As the hot rolling of steel moves into new more compact and effective processes, and as steel producers look for new ways to reduce their costs and increase their margins in ever tightening markets and tolerances, the evolution in Steckel mill technology, layouts, and new innovations may well keep the Steckel mill as a viable option, especially in areas of the world where minimized capital investments are required. In this paper we examine the evolution of the Steckel mills over the last two decades, with emphasis on new innovations and practical results, and provide a summary of hands on experience with some of these innovations. Also a focus on the South American Installations is given (from Siderperu to Gerdau's newest Combination- Plate-Steckel-Mill). In addition, we aim to show the viability of the Steckel mill as an option for many existing or prospective steel producers, as the quality of the products rolled with Steckel mills reaches new quality parameters and as new innovations permit the rolling of thinner and wider materials, reaching new applications and wider share in markets, while maintaining a strong foothold in the traditional uses of Steckel mill products such as stainless steel, structural, and line pipe materials. As the ability to handle heavier, thicker, and wider coiled plate products increases, the coiled plate Steckel mills option is as strong an option as ever.
\end{abstract}

Keywords: Hot rolling; Steckel; Innovation; Evolution; Viability. 


\section{INTRODUCTION}

Historically, Steckel mills which were invented in the 1930's, were used for limited purposes, especially as a workhorse for producing stainless steel products that were not susceptible to scale formation in the later stages of the rolling process, with lower specific weight requirements. The concept of using Steckel mills by steel producers took on a new life in the mid eighties of the last century, by trying to increase their range of use to include wide materials intended as coiled plate, and find ways to increase the specific weight of coils rolled on Steckel mills. The realization of cut-tolength lines that could handle wider, thicker, and heavier coils further enhanced the demand and use of such mills. This lead to new layouts allowing the use of Steckel mills to roll longer runouts, either by extending the length of roller tables (as was the case at Evraz Oregon Steel, Portland, Oregon, USA), or by adding flying shears on the exit side of the mill (as was the case at SSAB, Montpelier, lowa, USA, formerly IPSCO USA). This significant evolutionary step re-introduced the use of new Steckel mills, wider and more powerful, as a compact solution for mini-mills that can be installed in various areas of the world. This step proved quite successful, and lead to further installations of this type of Steckel mill again in the USA (SSAB, Mobile, Alabama, formerly IPSCO USA), and in China (Nanjing Iron and Steel company, NISCO) as also in Mexico (AHMSA) .

Another evolutionary step took place around the mid nineties of the last century, when Tippins (USA) and Samsung (South Korea) joined efforts to design a mini mill package that combined a medium thickness slab caster with a twin-stand Steckel mill. This invention was aimed as a cheaper alternative for strip production. This joined venture did not come to fruition, but the design was implemented 3 times around the world so far, with some variations in each installation. The first such mill was installed and commissioned in Ostrava, Czech Republic, in 1999, for Nova Hut (now Arcelor Mittal Ostrava). Being the first of its kind in the world, it experienced some difficulties during the startup. Once these difficulties were resolved, this mill's quality and quantity improved a lot, where within a couple of years it exceeded the designed level of 1 million tons per year, and is capable of rolling very thin material, such as $1200 \mathrm{~mm} \times 1.5 \mathrm{~mm}$. This mill produces all coils from hot charging of $150 \mathrm{~mm}$ slabs (original design was $125 \mathrm{~mm}$ slabs), of maximum length of $18 \mathrm{~m}$. This mill is equipped with roll shifting (hardly used), and with negative work roll bending (sometimes used). It was a fitted with backup roll lubrication system around 2008, with very good results reported on life of work rolls, etc

This installation was repeated in Kunming, China, in 2002. A different layout was used to the limitations of an existing building, which resulted in a shorter laminar cooling section. The startup of this mill was fast and successful, due to the experiences learned from the first installation. The mill entered into full production in 2003. This mill also uses hot charging of slabs, mainly $200 \mathrm{~mm}$ thick, and in various widths. There are 3 cold mills that use coils from the Steckel mill, and one Cut-toLength line that can handle coils up to $16 \mathrm{~mm}$ thick.

The last of these installations was for Maghreb Steel in Casablanca, Morocco. It is a similar layout as in Ostrava, but with slabs in the range of $200-250 \mathrm{~mm}$. It was commissioned in 2010. This mill is equipped with CVC roll design from SMS, and has also new HGC capsule design from SMS and a new upcoiler mandrel design. (insert layout if possible). This mill started its production during a crisis period, and has not relay gained footing on the market. 
All three traditional twin stand Steckel mills have experienced reasonable success in reaching their designed potential, even exceeding it times. They are able to supply a high percentage of their production for non-exposed cold rolled production, and meet other requirements as structural steels, silicon steels, API grade, HSLA, etc... They are all equipped with pinch roll shears, with various successes in the use of this application.

The pitfalls of these twin-stand Steckel mills can be summarized as follows:

- Inability to crop ends consistently in the rolling process, unless additional passes are incorporated to be able to shear a bit thicker ends.

- The distance between the distance is larger than normal in order to incorporate the edger.

- Inability to consistently handle the excessive ware on work rolls due to the roughing process.

The advancement in the control systems and the implementation of new layouts and ideas lead several of the existing Steckel mills with traditional layouts, to revamp their processes and meet higher demands from customers in terms of quality and quantity. An example of such revamps took place at Aperam (Formerly Acesita, Brazil), which was done over several phases and is described in more detail later.

There are two other notable revamps that are considered as a departure from traditional layouts:

SMS and Outokumpu joined efforts to redesign the Steckel mill at Outokumpu's site in Tornio / Finland, by installing 3 finishing stands after the Steckel mill. This lead to a significant increase in productivity and quality. It is not clear whether this revamp project achieved all of its designed parameters, especially in the area of minimum thickness rolled. It remains to date as the only revamp and change to layout of its kind.

SMS-Tippins and Jindal Stainless joined efforts to redesign the Steckel mill at JSL's site in HISAR, India. This change involved moving the exit coiling furnace downstream toward the downcoiler, and installing a second-hand stand $7.5 \mathrm{~m}$ downstream of the existing Steckel stand. A looper was installed between the two stands for tension control. Pinch roll shears were also installed to shear ends during the Steckel process and increase the yield. This project was executed in the $3^{\text {rd }}$ quarter of 2009. The main objectives were to increase the productivity and have better control on the head end thickness. To meet the first objective but due to space limitations, a second pre heat furnace was installed to heat slabs to 600 degrees where they were extracted and shifted to enter the main existing reheating furnace. The roughing of slabs remained at the existing roughing stand, which was equipped with a new control system. The existing rotary crop shear remains online but it is seldom used.

\section{STECKEL MILLS IN SOUTH AMERICA}

For a special look at the region of South America, we would like to present the following information, culminating in the latest Steckel mill installed at Gerdau, Ouro Branco, Brazil, which onto itself is an unprecedented success story, and the main motivation behind this paper. 


\subsection{Siderperu / Peru}

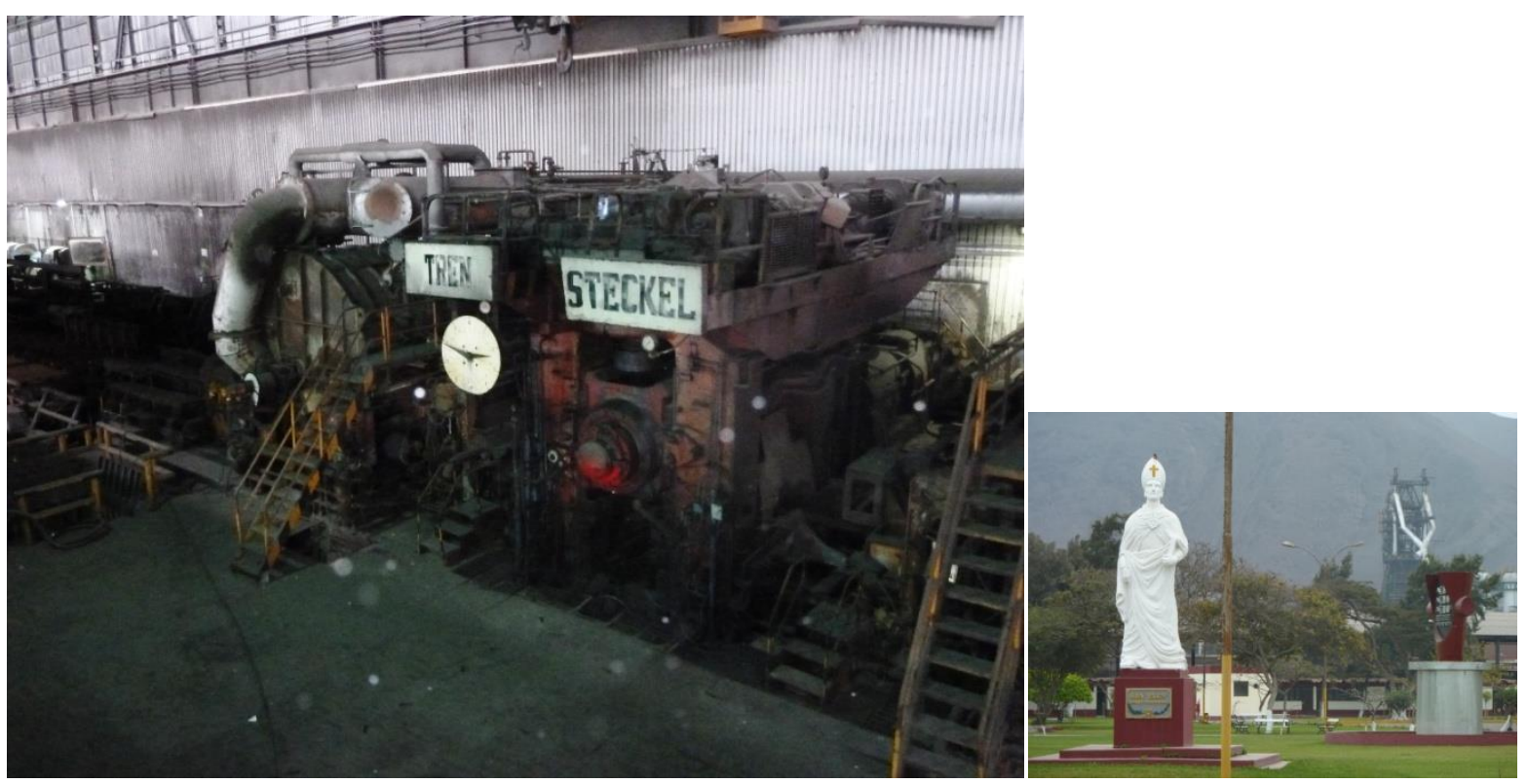

Fig. 1 Medium-wide-Band-Steckel-Mill at Siderperu (and "Saint Eloy", the responsible saint in charge, may have failed to revamp the mill....)

At Peru's former State-owned company Siderperu, one of the most ancients Steckel Mills is installed worldwide. A medium wide mill, that has been deactivated about two decades ago. The mill is still in reasonable conditions, and the upstream rougher is kept "fit for use" in order to produce again. But, this sounds rather like a fairytale, as it is not likely that for the Andean market suddenly has a demand on medium strip coming from an old mill.

\subsection{Paz del Rio / Columbia}

Is another historical mill installed, which is running medium wide products in a rather small amount (some 10 thousand tons a year) for the local market. Paz del Rio belongs to the Brazilian Votorantim Group, and mainly produces long products, but as shown in the below table, also flat products (rolled by a Steckel mill). Several studies were made to modernize the mill, although, obviously no major investments have occurred in the last years. 


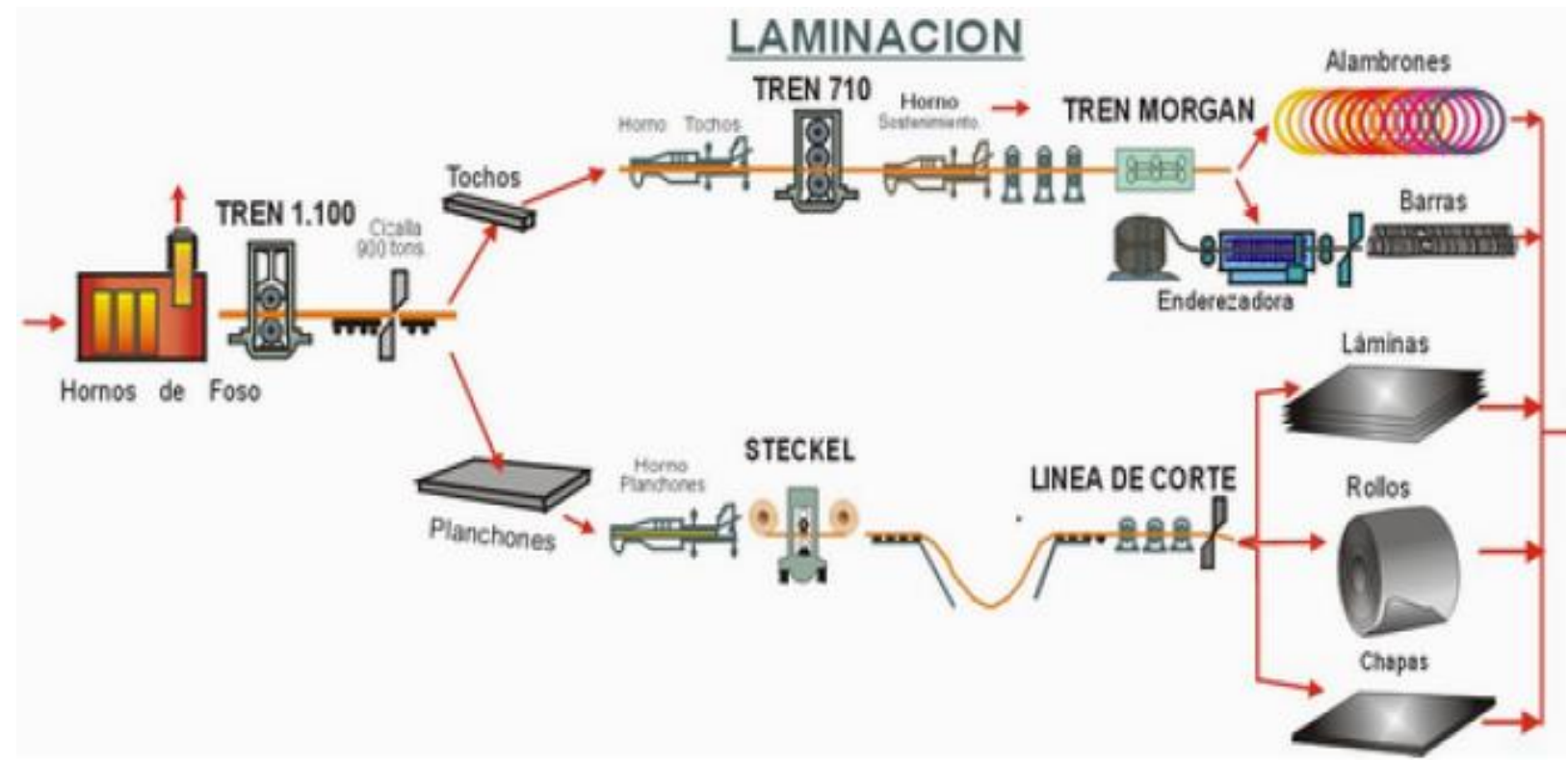

Fig. 2...Paz del Rio / rolling layout (Source Internet)

\subsection{Aperam (Acesita) Timóteo - MG Brasil}

Acisita's Mill was installed in late $70^{\text {th }}$ by Davy and has been revamped in 3 major modernizations, in order to increase productivity and throughput. AGC cylinders and control was the first modernization. Mill automation, reheating furnaces, laminar cooling, empowering of mill drives by a $3^{\text {rd }}$ main drive, coiler, etc, were the significant milestones in this long mill life time.

Strips of $1.9-14.0 \mathrm{~mm}$ thickness and $900-1550 \mathrm{~mm}$ width are produced. Acesita's mill produces mainly stainless strip, silicon grades but also carbon strip. The rougher is able to mill also heavy plates, cut by a static shear, side shifted and retracted before the finisher.

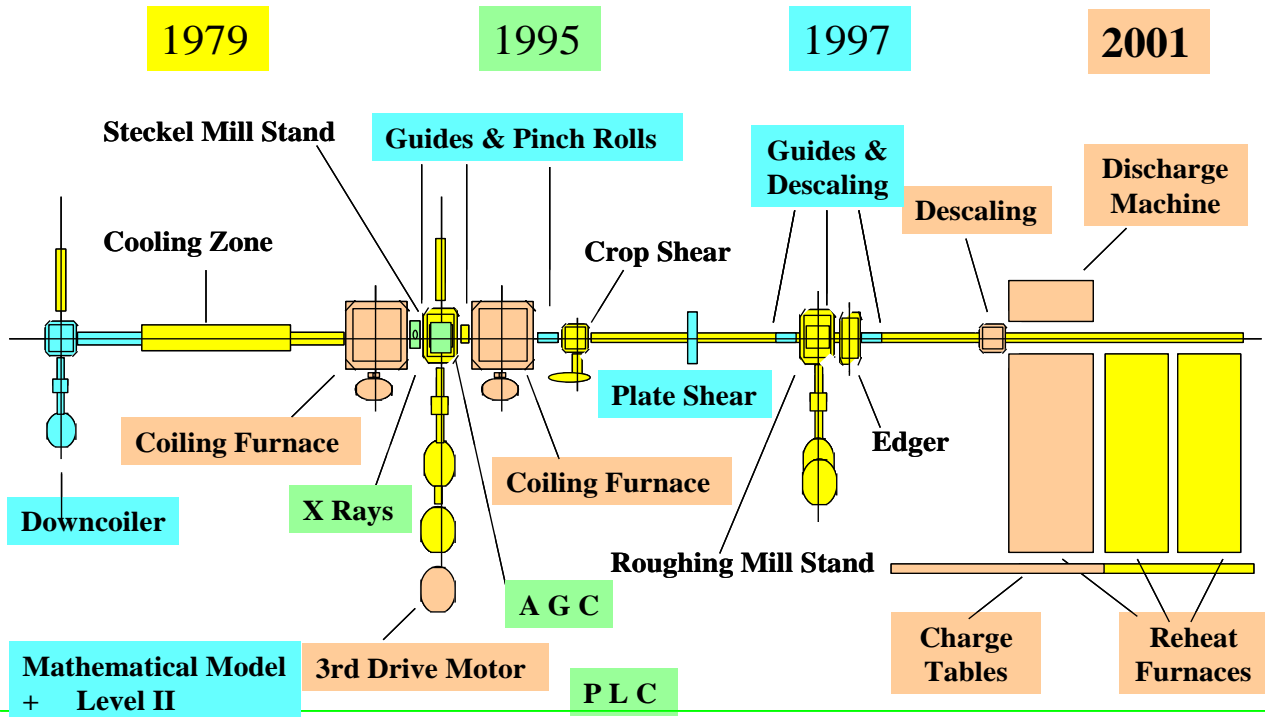

Fig.3 Acesita's Steckel Mill modernization Steps 


\begin{tabular}{|l|c|c|}
\hline \multicolumn{1}{|c|}{ PARAMETER } & 1979 & 2002 \\
\hline Production (tons/year) & 440.000 & 850.000 \\
\hline Basic products - $304(\mathrm{~mm})$ & $1250 \times 3,0$ & $1250 \times 2,5$ \\
\hline Coil Weight (tons) & 13 & 25 \\
\hline Productivity (tons/hour) & 65 & 128 \\
\hline
\end{tabular}

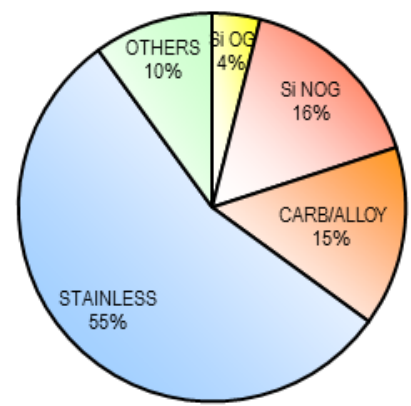

Fig. 4 Productivity gain along the modernisation steps and the challenging product mix [1]

\subsection{Gerdau's Combination Plate and Steckel Mill (CPSM)}

After a very detailed layout and technology discussion that went from a Plate-Steckel mill to a Twin-Stand Steckel, Gerdau finally opted for a combination of a Plate mill, to the left and a Steckel Mill to the right side, seen facing the furnaces. By doing so, Gerdau has nowadays the most versatile mill at hands and can produce coils (1.8 to $25 \mathrm{~mm}$ thick and up to $2100 \mathrm{~mm}$ wide) and plates from $5 \mathrm{~mm}$ to $150 \mathrm{~mm}$ thick with a maximum width of $3800 \mathrm{~mm}$.

As a first approach, Gerdau has invested in the finishing stands only (Steckel and Plate) and can in future add on the respective rougher(s). Also the $3^{\text {rd }}$ Reheating furnace is to be mounted in its foreseen place.

"This is the most versatile mill layout ever made, Gerdau's mill manager said, and it gives us the chance to complement the mill (by roughing mills and a $3^{\text {rd }}$ reheat furnace, as possibly also required finishing stands after the Steckel stand) whenever the market demands for more products". [2]

Further Gerdau stated, that the mill had a very successful ramp up, and had achieved the minimum thickness (and better) by achieving 1,8mm thickness, with only one mill stand in operation from a slab width starting of $220 \mathrm{~mm}$ [3].

The layout provides three reheat-furnaces where the first two are in operation since the beginning and the $3^{\text {rd }}$ one will be installed in future. Each side consists of a rougher and a finishing mill, one for plate and one for coil production (Steckel). The finishing mills are already started up (Steckel since two years) and in operation. The plate route is under hot commissioning and already producing sellable plates (status April 2016), with good quality.

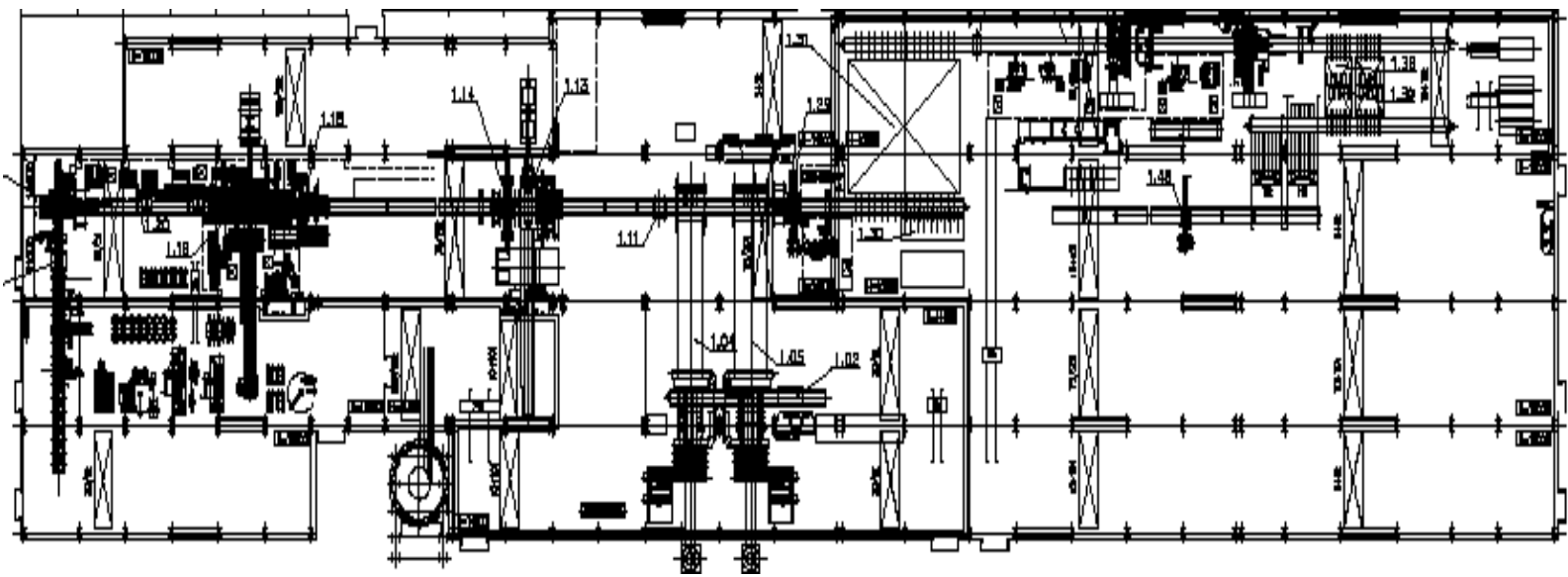

coil route

plate route

Fig 5 : schematic layout shows the coil and plate route fed by 2 ( future 3) reheating furnaces [4] 

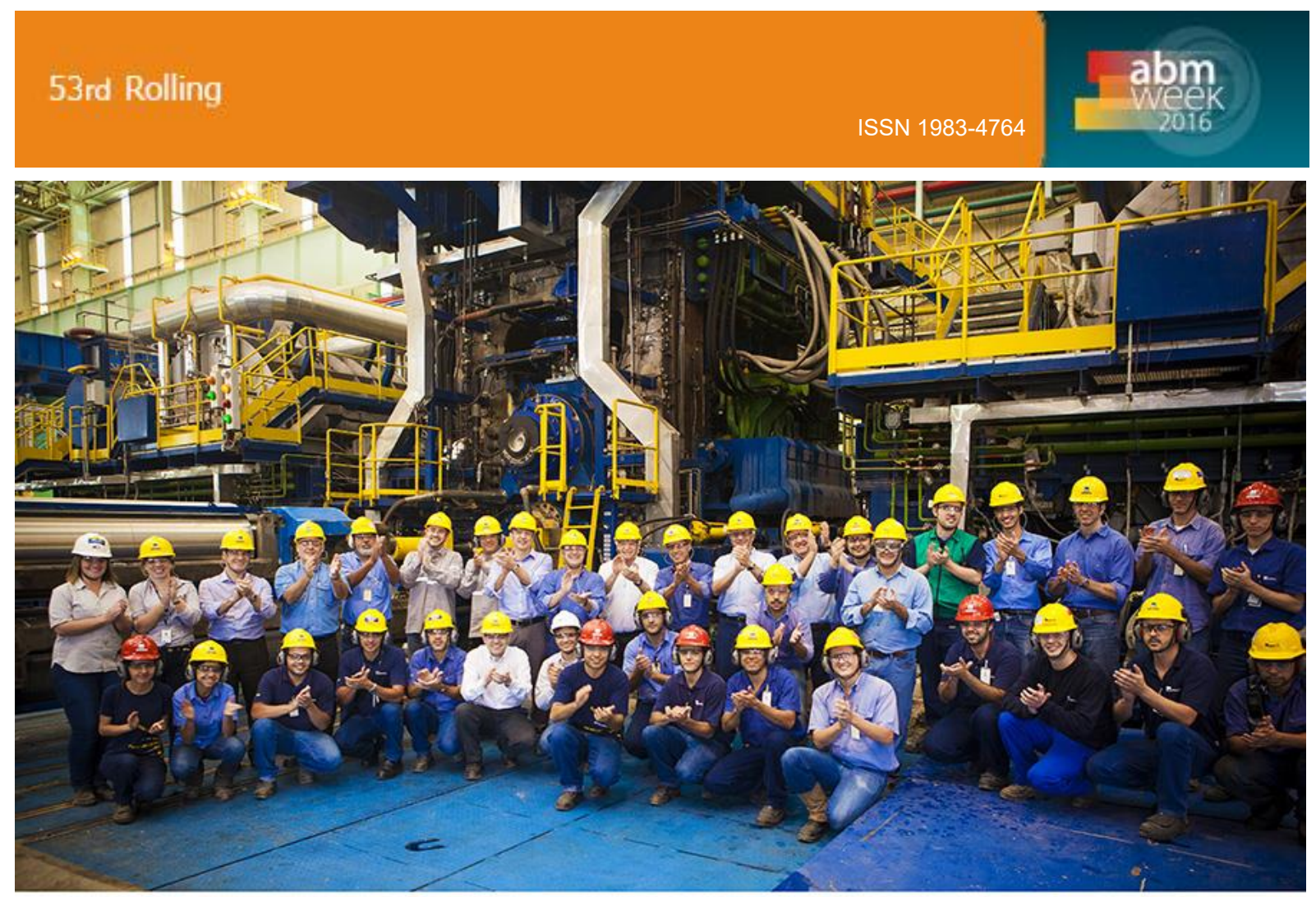

Usina Ouro Branco - Laminação de Planos - 13/11/2013

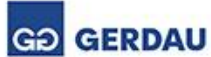

Fig 6 The JK Mill at Gerdau in Ouro Branco (Combination-Plate and Steckel-Mill) at Inauguration in $2013[5]$

\section{COMMON THREADS TO SUCCESS}

Below table shows the evolution of Steckel mills, from the classic $0+1$ mill to the Plate Steckel, as also to the Steckel with FM Stands.

\section{Steckel Mill Layouts}

\begin{tabular}{|c|c|c|c|}
\hline & \multirow{3}{*}{\begin{tabular}{|r|} 
Typical Capacity \\
0.8 million toa \\
\end{tabular}} & \multirow{3}{*}{$\begin{array}{l}\begin{array}{l}\text { Typical Strip Thickness/ } \\
\text { Width }\end{array} \\
\begin{array}{r}2.12 \mathrm{~mm} / \\
800-1650 \mathrm{~mm}\end{array}\end{array}$} \\
\hline & & & \\
\hline Single Stand Steckel Mill & (2) (2) & & \\
\hline Twin Steckel Mill & Qf? & 13 million toa & $\begin{array}{c}2-12 \mathrm{~mm} / \\
800-1650 \mathrm{~mm}\end{array}$ \\
\hline Steckel Mill with Rougher & (2) & 1 million toa & $\begin{array}{l}1.8-12 \mathrm{~mm} / \\
800-1650 / \\
2100 \mathrm{~mm}\end{array}$ \\
\hline $\begin{array}{l}\text { Steckel Mill with } 2 \text { or } 3 \text { additional } \\
\text { finishing stands }\end{array}$ & (2) 8:800 & 1.7 million toa & $\begin{array}{c}1.6-12 \mathrm{~mm} / \\
800-1800 \mathrm{~mm}\end{array}$ \\
\hline $\begin{array}{l}\text { Steckel Mill with additional Coiler } \\
\text { Furnace for multi-piece rolling }\end{array}$ & (290) & 0.8 million tog & $\begin{array}{c}2-12 \mathrm{~mm} / \\
800-1650 \mathrm{~mm}\end{array}$ \\
\hline \multirow[t]{2}{*}{$\begin{array}{l}\text { Plate-Steckel Mill } \\
\text { with single stand }\end{array}$} & & $\begin{array}{l}\text { Plates: } \\
\quad 0.75 \text { million toa }\end{array}$ & $\begin{array}{c}5-50 \mathrm{~mm} / \\
1600-3250 \mathrm{~mm}\end{array}$ \\
\hline & 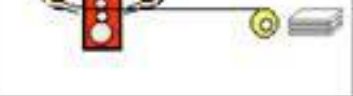 & $\begin{array}{l}\text { Strip: } \\
0.25 \text { million to }\end{array}$ & $\begin{array}{c}2.5 .20 \mathrm{~mm} / \\
1600-2500 \mathrm{~mm}\end{array}$ \\
\hline \multirow[t]{2}{*}{$\begin{array}{l}\text { Plate-Steckel Mill } \\
\text { with roughing stand }\end{array}$} & & $\begin{array}{l}\text { Plates } \\
\quad 1.1 \text { million toa }\end{array}$ & $\begin{array}{c}5.50 \mathrm{~mm} / \\
1600-3250 \mathrm{~mm}\end{array}$ \\
\hline & 8 & $\begin{array}{l}\text { Strip: } \\
0.4 \text { million toa }\end{array}$ & $\begin{array}{c}2.5 .20 \mathrm{~mm} / \\
1600-2500 \mathrm{~mm}\end{array}$ \\
\hline
\end{tabular}

Fig. 7 The evolution of Steckel mills within the last two decades as illustrated by VAI[6] 
It is interesting to note that these production figures and specifications are the basis for the design of these plants, and that in reality the existing mills based on some of these options have all exceeded these figures in total production, thinnest product, as well as the variation of the products they can roll.

As a case in study, we examine the success story of the Gerdau Steckel Mill, which as described earlier, was the fruit of very laborious and hard work between the end user and the supplier, taking into consideration many aspects such as the location of the plant, the demand on the local market, the future demand for export and higher qualities. Decades of experience were combined in order to produce the mill layout and set it in motion. We can summarize the threads to success in most of the projects that we participated in as follows:

- Know your market, set your target, and design the upstream and the downstream equipment to achieve your target. Case in point, the SSAB plants in USA, where a 120 " $(3 \mathrm{~m})$ width caster helps them achieve a very high rate of productivity, close to $120 \mathrm{kT} /$ month, while having suitable finishing lines to process such volume of steel. In addition, the Caster at Gerdau allows the production of the most common slab dimensions on the market, so that the export and direct sale of slabs in case the need to do so arises. The Steckel Mill at Gerdau has yet to go through very important expansion steps, but the layout already incorporates the space and foundations needed for these expansions. Even though the performance of the Gerdau Steckel mill has already reached high levels of quality and quantity, and in some cases exceeded the design parameters in its short existence, the limits of what is yet to be achieved is exciting and motivating.

\section{A SKILLED TEAM MAKES THE DIFFERENCE}

At this time, it is beneficial to focus on the ramp up phase of the steckel mill at Gerdau. Both customer and supplier Siemens-VAl (now Primetals) put a significant effort into developing a rigorous plan that ensured the most secure and successful startup of the plant, while reducing the required material, and shortening the time startups of this usually magnitude. The characteristics of this plan focused on bringing functions that the mill has into use just when they were needed to move into the next step of production, after ensuring that the previous steps attained the expected results. The plan defined what functions were required to reduce the thickness or increasing the width, and produce them with saleable quality within few short trials. This plan was adhered to almost on a daily basis, and the joint experience from both sides proved to be the catalyst for an unprecedented success. It is noteworthy that an extensive training period and system test took place at the supplier's facility, which helped in resolving many issues and getting the system into as close a stage as possible for startup and rolling. The execution of this plan and the ensuing extraordinary results demonstrate the possibilities of what the future holds for sub-developed countries, and in this case Brazil. Result-focused planning and execution can be carried on anywhere, with the help of a carefully assembled and trained teams:

- As a user, build and train a solid team that is ready by the time the mill is ready to roll.

- Go through variation of layouts, and incorporate space for growth and ease of access. 
- The first 3 months of operations are the most important in the life of the mill. Plan with diligence, prepare with vigilance, and execute with exigencies to make the best start possible.

- After the mill has been put into production, the end user needs to work with potential customers to introduce new products and entice them to use these products

\section{WHAT IS NEXT?}

The success experienced with new and alternative layouts of rolling mills and incorporating the use of Steckel mills, have lead suppliers to push the envelope even further, to reach new frontiers in this area. The incorporation of thin slab casters is something of increased interest, leading to new possibilities with layouts that include a combination of a roughing stand, coiling boxes, induction heaters, and a single or twin stand finishing mills. These layouts tend to solve some issues that are holding back the performance of the first generation twin stand Steckel mills, as mentioned in section 2. As was the case with the twin stand mills, once a couple of new layouts are realized and installed, a new investigation should be carried to evaluate their performance, but there should be little doubt about the usefulness of these ideas and layouts for new steel producers.

\section{CONCLUSION}

As a result of all the inventions and revamps mentioned above, a new look and appreciation of Steckel mills has taken place. In the last two decades, about 20 installations of Steckel mills have been put into operation, and there is renewed interest to install more of them, given the tight economic budgets for larger installations more room and a new future. Steckel mill technology will continue to go on with new innovations and enhancements in order to meet the changing markets. The Steckel Mill technology is such a flexible metallurgical tool, that more and new advancements will be made in future. A bright and promising future is to be predicted for Steckel mills.

\section{REFERENCES}

Luiz Otavio Procopio, Acesita's mill manager, Rolling Conference in Austria (2004) Jose Herbert Dolabela Silveira, Overall mill manager at Gerdau, Ouro Branco / Brazil Willy Schuwarten, Steckel mill manager at Gerdau, Ouro Branco / Brazil

Gerdau's Combination Plate Stecke Mill CPSM (Layout Variant)

Inauguration of Steckel mill in Ouro Branco (Source Gerdau)

Steckel Mill overview by VAI (now PRIMETALS) 